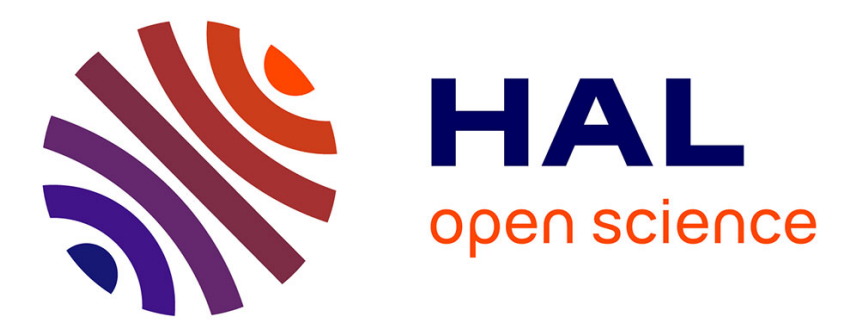

\title{
Model-based evidence of the dominance of the guitar brace design over material and climatic variability for dynamic behaviors
}

Romain Viala, Vincent Placet, Scott Cogan

\section{- To cite this version:}

Romain Viala, Vincent Placet, Scott Cogan. Model-based evidence of the dominance of the guitar brace design over material and climatic variability for dynamic behaviors. Applied Acoustics, 2021, 182, pp.108275. 10.1016/j.apacoust.2021.108275 . hal-03451511

\author{
HAL Id: hal-03451511 \\ https://hal.science/hal-03451511
}

Submitted on 8 Dec 2021

HAL is a multi-disciplinary open access archive for the deposit and dissemination of scientific research documents, whether they are published or not. The documents may come from teaching and research institutions in France or abroad, or from public or private research centers.
L'archive ouverte pluridisciplinaire HAL, est destinée au dépôt et à la diffusion de documents scientifiques de niveau recherche, publiés ou non, émanant des établissements d'enseignement et de recherche français ou étrangers, des laboratoires publics ou privés. 


\title{
Model-based evidence of the dominance of the guitar brace design over material and climatic variability for dynamic behaviors
}

\author{
Romain Viala ${ }^{\mathrm{a}}$, Vincent Placet $^{\mathrm{b}}$, Scott Cogan ${ }^{\mathrm{b}}$ \\ ${ }^{a}$ Institut Technologique Européen des Métiers de la Musique - ITEMM, 71 Avenue O. \\ Messiaen - 72000 Le Mans \\ Laboratoire d'Acoustique de l'Université du Mans - LAUM CNRS 6613 - Le Mans \\ Université, Avenue Olivier Messiaen, 72085 Le Mans Cedex 09, France \\ ${ }^{b}$ Univ. Bourgogne Franche-Comté, FEMTO-ST Institute, CNRS/UFC/ENSMM/UTBM \\ Department of Applied Mechanics, 25000 BESANÇON-FR, Tel. : +(33 3)81666010
}

\begin{abstract}
It is generally alleged that the design choices of acoustic guitar bracing patterns lead to a specific sound of the instrument. However, in the presence of strong uncertainties due to variability of material properties and climatic conditions, the robustness of the soundboard dynamics has yet to be investigated. In this study, three types of bracing patterns are studied using physics-based models and stochastic analyses are performed to account for material and climatic uncertainties. It is shown that the choice of a brace design leads, at least in the low frequency domain, to a dynamic behaviour that is not stackable with another design, even in the presence of strong aleatory uncertainties. This assessment supports the conjecture that guitar brace design choices have a greater impact than material variability where guitar soundboard dynamics are concerned. More generally, these results illustrate the usefulness of detailed physics-based models in the understanding, design and making of guitars.
\end{abstract}

Keywords: Physics-based modelling, Virtual prototyping, Uncertainty quantification, Screening analyses, Guitar braces, Spruce tonewood

Email address: romain.viala@itemm.fr () 


\section{1. Introduction}

Part of this work and results and figures have been published in the $\mathrm{PhD}$ of first author [1], whose download link is given in reference. Acoustic guitars comprise a wide range of instrument types, prices and qualities. Different families of instruments exist each with specific orientations and shapes of the stiffening ribs known as bracing patterns. During the fabrication process, guitar makers adapt the bracing design to insure a desired static and dynamic behaviours of the soundboard. It is often alleged that the design of a guitar is more important than its material properties. This implies that the design choices made by a guitar maker to achieve a desired behavior go beyond the injunction to simply use the "best" tonweoods. Moreover, some instrument makers have purposely used low quality wood to support this idea [2]. Nevertheless, it remains a belief, shared by instrument makers and many musicians, that high grade woods and specific species are key factors involved in achieving a desired guitar sound [3]. Considering that current wood availability issues affect more and more wood species, it is reasonable to ask if this approach remains valid.

Musicians attribute a specific sound and timbre of the instrument depending on the wood species and its anatomical features. However, this attitude is not justified and generally belied by rigorous studies. In [4], it was shown that musicians could not distinguish between guitars with backs made with different wood species. The material properties of the wood of a given specie vary widely, and an overlap may be possible with other species, which may explain why a specific wood specie may not be identified.

Acoustic guitar dynamics have been the subject of many studies, based on analytical and experimental approaches but also numerical methods using physics-based models. The experimental approach has been used for decades to observe the resonance modes of guitar soundboards, either isolated or when coupled with the sides and the remaining parts. As an example, it has been 
used in a deterministic manner for the comparison of different guitar families in relation to their bracing patterns [5]. The experimental approach is also useful to study the global dynamics of the guitar and its radiated sound by dealing with a macro response of the instrument $[6,7]$.

More instrument making based studies have also been performed. As an example, the different fabrication steps have been studied to evaluate their impact throughout the construction process, using modal testing [8] or both models and experiments [9]. In order to highlight the variability of the guitar behaviors, even when their geometries are identical, other experimental techniques have been used, such as studying the bridge admittance [10] as detailed in [11]. Similarly, the impact of the bridge has been investigated using experimental harmonic analysis, visualisation, and simulation techniques [12].

These different approaches have proven useful for the study of the impact of the bars on the guitar body response, [13] and to compare them to nominally identical numerical models of the body, where the variability of the wood was not implemented [14]. Using the Chladni method, it has been shown that, for a given body shape, the differences in the body dynamics made of different braces increase with the frequency [15]. Experimentally, at low frequencies, the deformed shapes were similar, but later the different areas created by the braces exhibited very different behaviour. Moreover, it has also been observed that, for the perception of a sound and timbre, the damping and frequency of the modes may be less important than the effective mass and area of the considered modes $[8,9]$. Despite the fact of studying existing instruments, experimental studies are limited when considering the relationship between instrument makers geometrical choices and the measured dynamic features. The main reasons for these limitations are the wood variability, the irreversibility of the modifications, as well as the time and cost of such approaches. To overcome these limitations, physics-based models are now considered as a powerful method that enable the study of a parameter effect, where all else unchanged.

Physics-based models of guitars have been developed for decades [16]. The 
evolution of computational power enabled more and more sophisticated models such as the complete processus of the production of sound, from the plucked guitar string to the radiated sound [17]. One of the most complex model, combining complete structure and fluid-structure interactions, has been developed in [18] and enabled the computation of the radiated sound around the instrument. More recently, models have reached an even higher level of detail, and simulated the interactions and collisions that occur on several kinds of acoustic guitars, such as the viola Caipira [19].

In addition to the computation of the modal basis of guitar soundboards, the models have been used to compute the bridge admittance of the guitar [20]. Another feature, the complex frequency domain assurance criterion has been used to evaluate the impact of a non-invasive restoration [21] and validate a model [22]. As for the violin, methods have been proposed to modify the shape of the braces to tune specific modes, and the height of the braces has been considered as the most influential parameter [23]. Recently, in [24], a study has performed the optimization of the geometrical characteristics of guitar soundboards (thickness of the top and height of the braces) based on the sound pressure level output. But such methods are only justified if the brace patterns have more impact on guitar behaviour than the full variability of wood.

Hence the importance of comparing the relative influences of wood variability and brace design on the vibratory behaviour of guitars.

Toward this end, physics-based models will be used to explore the modal behavior of a large number of soundboard characterisitics taking into account uncertainty in both the material properties (spruce tonewood and braces) and the climatic conditions (temperature and humidity). Therefore, stochastic simulations are needed to describe the probabilistic nature of the parameters of a wood specie and climate.

In the next section, the finite element models and analyses are described. Then, the results are given and discussed. Finally, a conclusion sums up the key 
results of this study and gives perspectives for further studies.

\section{Models and methods}

Three guitar bracing patterns will be considered with all else unchanged.

- The classical nylon string guitar $\left(C_{\text {guitar }}\right)$, has a soundboard made of spruce or western red cedar. The braces are perpendicular to the soundboard grain with bars on the top part and fan-like bars on the bottom part of the soundboard.

- The steel-string acoustic guitar $\left(A_{\text {guitar }}\right)$ is generally built in different body types. One of the characteristics of this type of guitar is the cross shaped braces.

- The Selmer guitar $\left(S_{\text {guitar }}\right)$ is a type of steel string guitar. This style of guitar generally has a small oval or "D" shaped sound-hole along with a cutaway. The braces are glued perpendicular to the grain.

\subsection{Soundboard geometry}

The models possess different brace types but the same sound-hole, rosette, bridge and cutaway. The geometries considered here are inspired from traditional templates. The template for the classical guitar is provided by the book "classical guitar making" [25], the template for the Selmer guitar brace is provided by François Charle [26], a luthier in Paris. The steel string guitar style braces are inspired from the book "Build your own acoustic guitar" [27]. The geometries of the three soundboards are made with the computer-aided design (CAD) software SOLIDWORKS ${ }^{\circledR}$. Top and bottom view of the soundboards are represented in the figure 1 . The side of the soundboards where the bridge, saddle and rosette are represented are the same for each soundboard and their material parameters are fixed. For the three soundboards considered, only the other sides where the braces are glued are different. The thickness of each soundboard without braces is equal to $3 \mathrm{~mm}$. The guitars with classical, steel string and Selmer braces will be labeled $C_{\text {guitar }}, A_{\text {guitar }}$, and $S_{\text {guitar }}$, respectively. 


\subsection{Meshing of the assembly}

The CAD are imported into PATRAN ${ }^{\circledR}$ and the volumes (generally up to 20) are meshed with tetrahedral elements with quadratic interpolation (TET10) to increase the number of degrees of freedom in the thickness and avoid bending issues of solid elements. The mesh shows coincident nodes at the numerous interfaces. At the end of the process, the number of elements depend on the brace types and are close to 58000 elements and 105000 nodes. Once the volumes are meshed, clamped boundary conditions are applied to the contour of the soundboard. This is evidently an idealization the soundboard is in reality glued on the sides and linings and some parts of the soundboard are removed to glue the bindings. Once the mesh and the boundary conditions are completed, the material properties are introduced.

\subsection{Material properties}

The material properties introduced to represent the spruce variability are given in the table 2 [28]. The dependence of the material properties with respect to the relative humidity is taken from [1]. The guitar soundboard and bars are entirely made of spruce wood which is treated as an orthotropic material. It is defined with 12 parameters, three Young's moduli $E_{i}$, three Coulomb's moduli $G_{i j}=G_{j i}$ and six Poisson's ratios. The Poisson's ratio are related by the equation $\frac{\nu_{i j}}{E_{i}}=\frac{\nu j i}{E_{j}}$. The bridge and rosette are often made of rosewood, Dalbergia which represents a wide variety of species. The properties of the rosewood parts are given in the table 1 [29], [30], [31]. It is a denser wood than spruce but exhibits similar rigidity in the longitudinal direction, and twice the rigidity in radial direction. The saddle is made of polyoxymethylene (POM). The POM is defined as an isotropic material with Young's modulus, Poisson's ratio and specific gravity equal to $3.1 \mathrm{GPa}, 0.35$ and 1.42 respectively. Once the material parameters are introduced in the model, it is possible to estimate the mass of the three soundboards, which are reported in the table 3 . 
The mass of the three soundboards vary with a maximum difference of 58 g, over $20 \%$ more compared to the lightest soundboard (classical braces). The braces may significantly increase the mass which tends to inhibit the radiation of the sound. Moreover, this higher mass is supposed to decrease the resonance frequencies, although the stiffening effect of the bars may compensate this effect, especially when oriented perpendicular to the grain braces. Once the models are complete, they are used to compute the eigenmodes of each brace configuration. The prestress state is not taken into account in the model, nevertheless, it has been shown that prestressing a plate in vibration tends to increase or decrease the eigenfrequencies of the plate depending on the degree of plate curvature [32]. The current comparison aims to highlight trends instead of exact vibratory behaviour of the soundboards, and thus, the models are simplified.

\subsection{Eigensolution calculation}

The solution of the eigenvalue problem yields the undamped model eigenvalues. The modal basis is computed in the $[20 ; 2500 \mathrm{~Hz}]$ frequency band and leads to a number of modes comprised between 40 and 50. For each eigenmode, the deformed shapes are displayed and the bridge admittance is computed with the modal superposition method. A modal damping ratio based on the experimental values is used $(\xi=1.15 \%)[22]$ for the bridge admittance calculation. In this study, a stochastic analysis is performed based on the probabilistic definition of the material parameters. For each brace configuration, 1000 computations are performed and the features of interest are extracted.

\subsection{Morris sensitivity analysis}

A Morris sensitivity analysis is performed [33] as described in [28]. Five stiffnesses and the density of each component, in addition to the temperature and the relative humidity are considered. The implementation of the dependence of the material properties with respect to the climatic parameters is similar to that found in [28], [1]. The material parameters and their nomenclature, used in the 
results section, are given in the table 4 . In total, 14 parameters are considered for the sensitivity analysis, and the Morris sensitivity analysis is performed with 20 trajectories, leading to 301 runs $(14$ parameters $+1 \times 20$ trajectories +1$)$.

\subsection{Modal overlap factor}

The modal overlap factor (MOF) has been calculated for the defined third octave band and for all of the soundboard simulations. The low frequency domain (L.F.) is generally considered for a MOF inferior to 0.3. The mid frequency domain is considered for a MOF comprised between 0.3 and 0.7 and the MOF is calculated according to eq. 1 ,

$$
M O F=M_{d} \times f_{c} \times \eta
$$

with $M_{d}$ the modal density by third octave bands, $f_{c}$ the central frequency of the third octave band. The modal density is given by eq. 2 ,

$$
M_{d}=\frac{\Delta N_{m}}{\Delta f}
$$

where $\Delta N_{m}$ represents the number of modes that exist in a specific bandwidth $\Delta f$, the bandwidths is defined as third octave band here. $\eta$ is the loss factor of the system in the bandwidth and is considered here equal to $2.3 \%$, which is twice the modal damping value measured on guitar soundboards in [22], [10].

\subsection{Out of plane bridge admittance}

The bridge admittance is computed on the point shown in the figure 3 . The out-of-plane displacement $(\mathrm{Z})$ is considered for a given input force in both $\mathrm{X}$ and $\mathrm{Z}$ directions equal to $1 \mathrm{~N}$, which represents the input force of a string exhibiting motion in the XZ plane.

\subsection{Correlation coefficient}

In addition, a correlation coefficient is proposed to evaluate the relation between the material/climatic parameters and the bridge admittance amplitude. 
This feature will be used to evaluate which parameter has an influence on the value of the bridge admittance, for each frequency step, and gives the effective domains of a parameter in regard with the vibratory response of a given structure. For two variables $X_{i}$ and $X_{j}$, the correlation coefficient is given by the eq. 3.

$$
C=\frac{\operatorname{Cov}\left(X_{i}, X_{j}\right)}{\sigma_{X_{i}} \sigma_{X_{j}}}
$$

With $\operatorname{Cov}\left(X_{i}, X_{j}\right)$ the covariance between the variables $X_{i}$ and $X_{j}$, and $\sigma_{X_{i}}$ and $\sigma_{X_{j}}$ their respective standard deviation.

\section{Results \& discussion}

In this section, the results obtained with the 1000 computations of each cases are given. Firstly, a basic comparison of the modal basis of the three cases with initial values are given to qualitatively compare the soundboards.

\subsection{Deterministic results}

The modal bases of each nominal configuration are given in this section. The three modal bases possess up to 50 modes in the $[20 ; 2500 \mathrm{~Hz}]$ frequency band. The first eight modes of each family of soundboard brace patterns are displayed in the figures 4,5 , and 6 .

The deformed shapes are shown for comparison : the first mode of each soundboards is a monopole mode, which is an expected result, nevertheless, the zone associated with this mode differs for each brace family. Considering the frequency of the first mode, the average value is equal to 216,169 and $291 \mathrm{~Hz}$ for $C_{\text {guitar }}, A_{\text {guitar }}$ and $S_{\text {guitar }}$, respectively, with a coefficient of variation comprised between 5 and $6 \%$. Although the studied soundboard, thickness shape (with a cutaway), bridge type and sound hole size is a mix of different type of guitars, the trends are similar for real soundboards, whose first monopole is close to 200, 188 and $250 \mathrm{~Hz}$ for $C_{\text {guitar }}$ [34], $A_{\text {guitar [4] }}$ and $S_{\text {guitar }}$ [35] respectively. Nevertheless, the high variability in term of soundboard shape and thickness, sound hole size and brace modifications prevent from consolidated 
test-model comparisons. The soundboards exhibit dipoles in both the $\mathrm{X}$ and $\mathrm{Y}$ directions, not necessarily in the same order. As an example, the frequency of the dipole mode of $S_{\text {guitar }}$ in the $\mathrm{X}$ direction is much higher than the other cases, which can be easily linked to the bars mainly glued in the $\mathrm{X}$ direction, where the rigidity of the soundboard (radial direction) is much smaller than in the Y (longitudinal) direction. Besides these simple modes, it is seen that the deformed shapes become rapidly more complex and the modes of the different configurations are no longer comparable as shown by the Modal Assurance Criterion. The detailed MAC of the modal basis of each configuration compared two at a time is given in the table 5 .

This table shows that, out a total of 50 modes computed for each case, only a few modes exhibit close deformed shapes in the low frequencies domain, which is coherent with the results of [36], [13], [14] and [15]. The matched eigenfrequencies error is very high and it is clearly seen that the vibratory behaviour of the soundboards is very different in the considered frequency domain and for the nominal designs. The bridge admittances are shown in the figure 7 . These curves are constructed with the modal bases and thus are consistent with the eigenfrequencies and the eigemode shapes at the driving point used for the admittance synthesis. Considering the first peak related to mode 1, a large frequency discrepancy is observed. Nevertheless, above 400 Hertz, these differences are smaller and bridge admittances can be similar despite the differences observed in the eigenmode shapes. The bridge admittance is a local evaluation and does not reflect the complete shapes of the eigenmodes.

\subsection{Morris screening analysis results}

Figure 8 shows the results of the Morris sensitivity analyses for each brace configuration. These results highlight a small dominance of the soundboard properties over the brace properties, regardless of the brace pattern. The longitudinal specific modulus and densities of the soundboard and braces are the most important, and the impact of the relative humidity is relatively high. Then the specific radial modulus followed by the shear modulus in plane LR. Moreover, 
it is shown that the ranking of the parameters depends of the brace configuration. For the remainder of the stochastic study, only the longitudinal and radial Young's moduli, and LR shear modulus of the soundboard and braces have been considered as uncertain elastic parameters.

\subsection{Modal overlap factor}

The modal overlap factors for the three soundboard configurations are displayed in figure 9 and detailed in the table 6 . This figure shows that the modal overlap factor values and evolutions are similar for each soundboard, even though these structures exhibit very different modal behaviour. The Selmer guitar exhibits nevertheless a smaller modal overlap factor between 1250 and 2500 $\mathrm{Hz}$. The mid frequency domain is reached for a frequency value comprised between 800 and $1200 \mathrm{HZ}$, which is the limit of a modal point of view. The high frequency domain is reached for frequencies comprised between 1600 and 2000 Hz. Above these values, modal analysis is no longer relevant since modes can no longer be differentiated, and energy methods should be preferred [37].

\subsection{Stochastic results}

The results of the 1000 computations are shown using different formats : the frequency dispersion of the first ten modes of the guitar soundboards, the statistics and fuzzy-FRF of their admittance, and the correlation coefficient between the parameters and the value of the FRF for each frequency step. The table 7 indicates the dispersion in the eigenfrequencies of a soundboard given the variability in its material parameters. The RSD of the eigenfrequencies of each cases is close to $\pm 5.5 \%$, which means that up to $68 \%$ of the computed eigenfrequencies are between this value. Hence, in order to ensure that a design leads to different dynamics, the difference in the eigenfrequencies should be higher than $5.5 \%$. 
All the bridge admittances are summed up in the figure 10 which displays mean admittance and lower and upper limit for each brace pattern. Up to $350 \mathrm{~Hz}$, the FRF shapes of each cases are very different. The $A_{\text {guitar }}$ exhibits the lowest eigenfrequency of the first mode and the lowest absolute dispersion ([145;200], centered at $170 \mathrm{~Hz})$. The $C_{\text {guitar }}$ exhibits intermediate frequency of the first mode and absolute dispersion ([180;250], centered at $215 \mathrm{~Hz})$. The $S_{\text {guitar }}$ exhibits the highest frequency of the first mode, suggesting much higher stiffness (also considering its higher mass) and absolute dispersion $([250 ; 340]$ $\mathrm{Hz}$, centered at $290 \mathrm{~Hz}$ ). The relative dispersion of each FRF upper and lower limits are all close to $30 \%$. The difference between the mean FRFs decreases above $400 \mathrm{~Hz}$. The $C_{\text {guitar }}$ and $S_{\text {guitar }}$ bridge admittances are quite similar between 400 and $800 \mathrm{~Hz}$, in term of average level and lower and upper FRF limits. Considering these features, between 600 and $750 \mathrm{~Hz}$, the $A_{\text {guitar }}$ levels are very different from the two other configurations. Despite these observations, above $400 \mathrm{~Hz}$ the bridge admittances seem to merge together.

These results have to be compared with those given by the fuzzy-FRFs, displayed in the figure 11. In this figure, the dispersion in both amplitude and frequency of the bridge admittance is given for the three bracing patterns. The impact of the first mode on the low frequency admittance of the bridge is clearly seen for each type of braces. The maximum corresponding admittances of each case reach a similar value, close to $0.3,0.5$ and $0.2 \mathrm{~mm} / \mathrm{N}$ for $C_{\text {guitar }}, A_{\text {guitar }}$ and $S_{\text {guitar }}$, respectively. Above the frequency of the first mode, it is shown that the three bridge admittances are not superposed, even if the material properties and the climate conditions may strongly vary. The amplitudes are not similar above $300 \mathrm{~Hz}$, and each configuration exhibits complex responses, which is highlighted by this probabilistic point of view.

In order to study the influence of the previous parameters with respect to the frequency bands, the correlation coefficient is shown in figure 12. These results show that, depending on the brace pattern, the correlation between each material and climatic parameters and bridge admittance sampling varies. The 
longitudinal stiffness of the soundboard and the bars is strongly correlated with bridge admittance up to 220,160 and $290 \mathrm{~Hz}$ for $C_{\text {guitar }}, A_{\text {guitar }}$ and $S_{\text {guitar }}$, respectively. The $\mathrm{RH}$ is correlated with the FRF amplitude at 280 (which is also the case for $E_{L}$ of the bars) and $420 \mathrm{~Hz}$ especially, for $C_{\text {guitar }}$. For $A_{\text {guitar }}$, the RH is correlated with FRF magnitude especially in $[220 ; 340]$ (which is also the case for $E_{L}$ and $E_{R}$ of the soundboard) and $[600 ; 650] \mathrm{Hz}$ frequency bands. Numerous other correlations with parameters can be observed for the different braces patterns, as a function of the frequency bands. The results of the Morris sensitivity analysis are correlated, that is to say, the properties of the soundboard are most influential along with the relative humidity and the temperature. For the $S_{\text {guitar }}$, the braces seem to have a higher impact on the overall response. For this configuration the braces are larger and oriented perpendicular to the grain direction, which is a direction where the soundboard is significantly less stiff. Another output is observed where the figure shows some fringes. These fringes highlight the fact that some frequencies admittances are not influenced by any of the input parameters separately, as the coefficient correlation is equal to zero for each parameter, which is associated with an eigenfrequency.

\subsection{Discussion}

A screening analysis has demonstrated that longitudinal specific moduli and densities of soundboard and braces have the main impact on eigenfrequencies of the clamped soundboards, followed by the relative humidity, which is consistent with wood selection habits of guitar makers. The results show that material variability affect the dynamic features of guitars, such as eigenfrequencies, eigenmodes shapes and bridge admittances shape. Moreover, it is observed that the relative humidity also has a strong impact on the same features.

Nevertheless, it has been shown that the guitar maker design choices have a stronger impact on the dynamics of the soundboards. Indeed, the few matched eigenfrequencies are shifted in a more important way than with material and climatic changes. This highlights the dominant impact of braces on the low frequencies, in particular on the matched eigenmodes. For higher frequencies, the 
mode shapes are too different and they can no longer be matched between the different brace configurations. Moreover, it has been highlighted that for the perception of a sound and timbre, the damping and frequency of the modes may be less important than the effective mass and the zones of the considered modes [8]. This result is confirmed by the stochastic analyses results, especially fuzzy-FRF of each brace pattern configuration. There is no compensation effect due to the material variability that can lead to a similar vibratory behaviour of the structure. Hence, the design choices of the guitar makers can be considered as more influential than the wood choices and climatic changes, considering dynamic features such as eigenfrequencies, eigenmode shapes and bridge admittances. An important perspective to consolidate these findings is to perform perceptive tests, with sounds synthesized with the modal bases using a string model and verify that, whatever wood or climate variability, listeners would still clearly differentiate each type of brace. The correlation coefficient proposed here for material and climatic parameters is a key tool to highlight the link between the admittance amplitudes and the input parameters as a function of frequency. This post-processing tool, associated with the geometrical input parameters, may be used for further tuning of the guitar soundboard to reach a desired response in a reduced frequency band. The relative humidity appears to be important, but it has to be pointed out that the evolution of the material parameters of the wood when undergoing climatic changes are considered for a hygroscopic equilibrium state of the wood. In reality, these effects are not immediate and it is assumed that the wood stiffness is not fully modified by a climatic change. One of the main perspective of this work is to study small differences for each given brace pattern, by changing geometrical parameters of each brace one by one. Also, the impact of the different materials for the braces and soundboards (like other species or composites) with similar geometry needs to be investigated. 


\section{Conclusion}

In this paper, a physics-based model has been used to perform stochastic analyses on guitar soundboards with different brace patterns, corresponding to classical, steel-string and Selmer guitars. The comparison of the influence of material and climatic variability and guitar maker design choices has been performed in the dynamic domain. The results have shown that brace patterns have a higher impact on the dynamic features of a soundboard than material and climatic variability. The choice of a brace pattern family leads to dynamic behaviours that are not comparable with those of another family. This effect is not clearly apparent when considering the average and upper and lower bounds of the bridge admittances, but the fuzzy-FRF representation proposed gives more interesting insight. The main conclusion of this paper is that the design choices of brace shapes have a dominant impact on soundboard dynamics and that variations in wood density and stiffness is a second order effect. From an organological point of view, this provides a partial explanation for the existence of different guitars subcategories. Theses results and the methods proposed herein can provide decision support tools for instrument making, taking into account both geometrical and material changes. Futhermore, this approach can provide a basis for the robust optimisation of the guitar bracing patterns in order to develop designs that reproduce specific dynamic behaviours, for example of a specific appreciated instrument, even though the material and climate conditions may vary.

\section{Acknowledgements}

Funding : This work has been performed in the Framework of EUR EIPHI (ANR-17-EURE-0002). 


\section{References}

[1] Viala R. Towards a model-based decision support tool for stringed musical instrument making, Ph.D. thesis, Université Bourgogne Franche-comté; 2018.

[2] Gore T. Wood for Guitars, in : 161st Meeting Acoustical Society of America, Vol. 12 ; 2011. doi :10.1121/1.3610500.

[3] Bielski P, Kujawa M. Nonlinear modelling in time domain numerical analysis of stringed instrument dynamics, in : AIP Conference Proceedings, Vol. 1822, AIP Publishing; 2017. doi :10.1063/1.4977677.

[4] Carcagno S, Bucknall R, Woodhouse J, Fritz C, Plack CJ. Effect of back wood choice on the perceived quality of steel-string acoustic guitars, The Journal of the Acoustical Society of America 144 (6); 2018, 3533-3547. doi :10.1121/1.5084735.

[5] Caldersmith G. Designing a guitar family, Applied Acoustics 46 (1) ; 1995, 3-17. doi :10.1016/0003-682X(95)93949-I.

[6] Richardson B. Guitar making-the acoustician's tale, in : Proc. Second Vienna Talk, Vienna; 2010, pp. 125-128.

[7] Perry I. Sound Radiation Measuremets on Guitars and Other Stringed Musical Instruments, Ph.D. thesis, Cardiff University; 2014.

[8] Elejabarrieta MJ, Ezcurra A, Santamaria C. Evolution of the vibrational behavior of a guitar soundboard along successive construction phases by means of the modal analysis technique, The Journal of the Acoustical Society of America 108 (1); 2000, 369-78. doi :10.1121/1.429470.

[9] Inta R. The acoustics of the steel string guitar, Ph.D. thesis, The University of New south Wales; 2007. 
[10] Mansour H, Fréour V, Saitis C, Scavone GP. Post-classification of nominally identical steel-string guitars using bridge admittances, Acta Acustica united with Acustica 101 (2) ; 2015, 394-407. doi :10.3813/AAA.918835.

[11] Woodhouse J, Langley RS. Interpreting the input admittance of violins and guitars, Acta Acustica united with Acustica 98 (4);2012, 611-628. doi :10.3813/AAA.918542.

[12] Torres JA, Boullosa RR, Influence of the bridge on the vibrations of the top plate of a classical guitar, Applied Acoustics 70 (11-12); 2009, 1371-1377. doi :10.1016/j.apacoust.2009.07.002.

[13] Domnica SM, Curtu I, Dumitru L, Cretu N, Adriana S, Nastac S. A practical evaluation method of dynamical behaviour of classical guitar bodies, in : 13th International Research/Expert Conference, "Trends in the Development of Machinery and Associated Technology", Hammamet; 2009, pp. $565-568$.

[14] Curtu I, Stanciu MD, Cretu N, Rosca I. Modal Analysis of Different Types of Classical Guitar Bodies, in : Proceedings of the 10th WSEAS International Conference on ACOUSTICS \& MUSIC : THEROY \& APPLICATIONS, no. March, Prague; 2009, pp. 30-35.

[15] Curtu I, Stanciu MD, Grimberg R. Correlations between the plates' vibrations from the guitar's structure and the physical, mechanical and elastically characteristics of the composite materials, Amta '08 : Proceedings of the 9th Wseas International Conference on Acoustics \& Music: Theory \& Applications ; 2008, 55-60.

[16] Chaigne A. Numerical simulations of stringed instruments-today's situation and trends for the future, Catgut Acoustical Society Journal 4 (5); 2002, 12-20.

[17] Bécache E, Chaigne A, Derveaux G, Joly P. Numerical simulation of a gui- 
tar, Computers and Structures 83 (2-3) ; 2005, 107-126. doi :10.1016/B978008044046-0.50305-5.

[18] G. Derveaux. Modélisation numérique de la guitare acoustique, Ph.D. thesis, École Polytechnique; 2002.

[19] G. Paiva, Analyse modale vibroacoustique de caisse de résonance de Viola Caipira, Ph.D. thesis, Universidade Estadual de Campinas ; 2013.

[20] Elie B, Gautier F, David B. Macro parameters describing the mechanical behavior of classical guitars, The Journal of the Acoustical Society of America 132 (6) ; 2012, 4013-4024. doi :10.1121/1.4765077.

[21] Pérez MA, Manjón A, Ray J, Serra-López R. Experimental assessment of the effect of an eventual non-invasive intervention on a Torres guitar through vibration testing, Journal of Cultural Heritage 27; 2017, S103S111. doi :10.1016/j.culher.2016.04.011.

[22] Viala R, Perez MA, Placet V, Manjon A, Foltête E, Cogan S. Towards model-based approaches for musical instruments making : validation of the model of a Spanish guitar soundboard and characterization features proposal, Applied Acoustics 172; 2020. doi :10.1016/j.apacoust.2020.107591.

[23] Dumond P, Baddour N. Can a brace be used to control the frequencies of a plate?, SpringerPlus 2 (1); 2013, 1-14. doi :10.1186/2193-1801-2-558.

[24] Boven MV. Dynamic Response optimization of an acoustic guitar, Maste rthesis, Delft University of Technology; 2017

[25] Bogdanovitch JS. Classical guitar making. Sterling Publishing Co., Inc., New York; 2007.

[26] Charle F, Alexandre P. Plan guitare Selmer Maccaferri ; 2003.

[27] Kinkead J. Build your own acoustic guitar. Hal Leonard Corporation ; 2004. 
[28] Viala R, Placet V, Cogan S, Simultaneous non-destructive identification of multiple elastic and damping properties of spruce tonewood to improve grading, Journal of Cultural Heritage 42; 2020, 108-116. doi :10.1016/j.culher.2019.09.004.

[29] Sprossmann R, Zauer M, Wagenführ A. Characterization of acoustic and mechanical properties of common tropical woods used in classical guitars, Results in Physics 7; 2017, 1737-1742. doi :10.1016/j.rinp.2017.05.006.

[30] Guitard D, El Amri F. Modèles prévisionnels de comportement élastique tridimensionnel pour les bois feuillus et les bois résineux, Annales des sciences forestières $44(3) ; 1987,335-358$.

[31] Rossing TD. The science of stirng Insturments, Springer ; 2010.

[32] Mamou-Mani A. Précontraintes et vibration des tables d'harmonie, Ph.D. thesis; 2007.

[33] Morris MD, Factorial Sampling Plans for Preliminary Computational Experiments, Technometrics 33 (2); 1991, 161-174. arXiv :arXiv :1011.1669v3, doi :10.2307/1269043.

[34] Mihalcica M, Stanciu MD, Vlase S. Frequency response evaluation of guitar bodies with different bracing systems, Symmetry 12 (5); 2020. doi :10.3390/SYM12050795.

[35] Lee N, Chaigne A, Smith J, Arcas K. Measuring and Understanding the Gypsy guitar, in : Proc. of the Int. symposium on Musical Acoustics (ISMA07), September 9-12, Barcelona; 2007, pp. 1-8.

[36] Skrodzka E, Lapa A, Linde BBJ, Rosenfeld E, Modal parameters of two incomplete and complete guitars differing in the bracing pattern of the soundboard, The Journal of the Acoustical Society of America 130 (4); 2011, 2186-2194. 
[37] Boutillon X, Ege K. Vibroacoustics of the piano soundboard : Reduced models, mobility synthesis, and acoustical radiation regime, Journal of Sound and Vibration 332 (18); 2013, 4261-4279. arXiv :1305.3057, doi :10.1016/j.jsv.2013.03.015.

[38] Brémaud I, Gril J, Thibaut B. Anisotropy of wood vibrational properties : Dependence on grain angle and review of literature data, Wood Science and Technology 45 (4) ; 2011, 735-754. doi :10.1007/s00226-010-0393-8. 
Figure 1 - Computer aided designs of : (a) top view, (b) $C_{\text {guitar }}$, (c) $A_{\text {guitar }}$, (d) $S_{\text {guitar }}$.

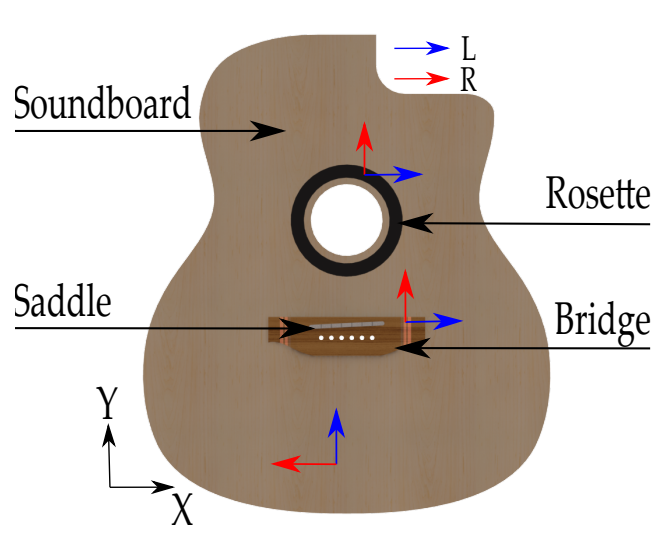

(a)

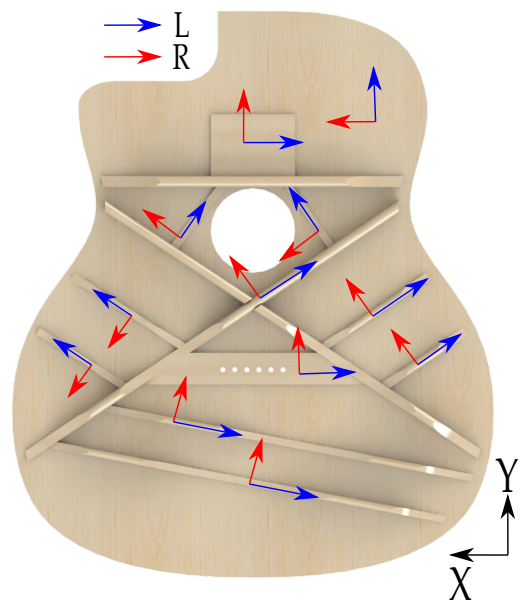

(c)

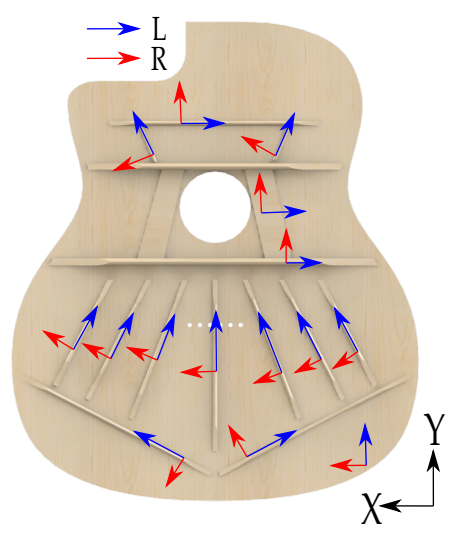

(b)

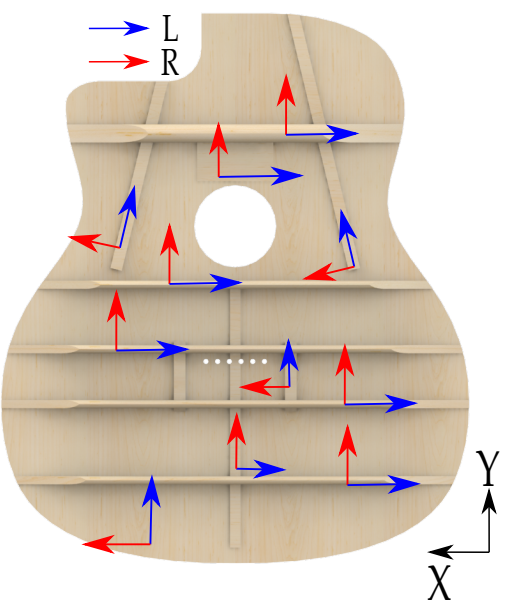

(d) 
TABLE 1 - Material properties of indian rosewood for bridge and rosette[29, 30, 31].

\begin{tabular}{cc}
\multicolumn{2}{c}{ Rosewood (Dalbergia) } \\
\hline Material parameter & Value \\
$E_{L}(\mathrm{GPa})$ & 13.3 \\
$E_{R}(\mathrm{GPa})$ & 1.7 \\
$E_{T}(\mathrm{GPa})$ & 1.0 \\
$\nu_{L R}$ & 0.38 \\
$\nu_{R T}$ & 0.49 \\
$\nu_{T L}$ & 0.02 \\
$G_{L R}(\mathrm{GPa})$ & 0.93 \\
$G_{R T}(\mathrm{GPa})$ & 0.2 \\
$G_{T L}(\mathrm{GPa})$ & 0.8 \\
$d(-)$ & 0.79 \\
\hline
\end{tabular}

TABLE 2 - Material properties of spruce implemented in the models, italic from [28] at $M C=$ $10 \%$. Remaining values from [30] and [38].

\begin{tabular}{cccc} 
Parameter & Spruce & Min. value & Max. value \\
\hline$\frac{E_{L}}{\rho}\left(\mathrm{MPag}^{-1} \mathrm{~cm}^{-3}\right)$ & 29000 & 20590 & 35380 \\
$\frac{E_{R}}{\rho}\left(\mathrm{MPag}^{-1} \mathrm{~cm}^{-3}\right)$ & 2280 & 1460 & 3810 \\
$\frac{E_{T}}{\rho}\left(\mathrm{MPag}^{-1} \mathrm{~cm}^{-3}\right)$ & 1480 & 1300 & 1660 \\
$\nu_{L R}(-)$ & 0.37 & - & - \\
$\nu_{R T}(-)$ & 0.48 & - & - \\
$\nu_{T L}(-)$ & 0.02 & - & - \\
$\frac{G_{L R}}{\rho}\left(\mathrm{MPag}^{-1} \mathrm{~cm}^{-3}\right)$ & 1850 & 1295 & 2442 \\
$\frac{G_{R T}}{\rho}\left(\mathrm{MPag}^{-1} \mathrm{~cm}^{-3}\right)$ & 100 & 74 & 150 \\
$\frac{G_{T L}}{\rho}\left(\mathrm{MPag}^{-1} \mathrm{~cm}^{-3}\right)$ & 1910 & 1070 & 2750 \\
Density $\left(\mathrm{g} \mathrm{cm}^{-3}\right)$ & 0.44 & 0.39 & 0.51 \\
Relative humidity $(\%)$ & 50 & 20 & 85 \\
Temperature $\left({ }^{\circ} \mathrm{C}\right)$ & 21 & 15 & 35 \\
\hline
\end{tabular}

TABle 3 - Physical properties of the soundboard models.

\begin{tabular}{cccc} 
Parameter & $C_{\text {guitar }}$ & $A_{\text {guitar }}$ & $S_{\text {guitar }}$ \\
\hline Mass $(\mathrm{g})$ & 237 & 244 & 295 \\
Volume $\left(\mathrm{cm}^{3}\right)$ & 516 & 571 & 647 \\
\hline
\end{tabular}


Figure 2 - (a), dimensions of the soundboard; (b), dimensions of the rosette; (c), dimensions of the bridge.

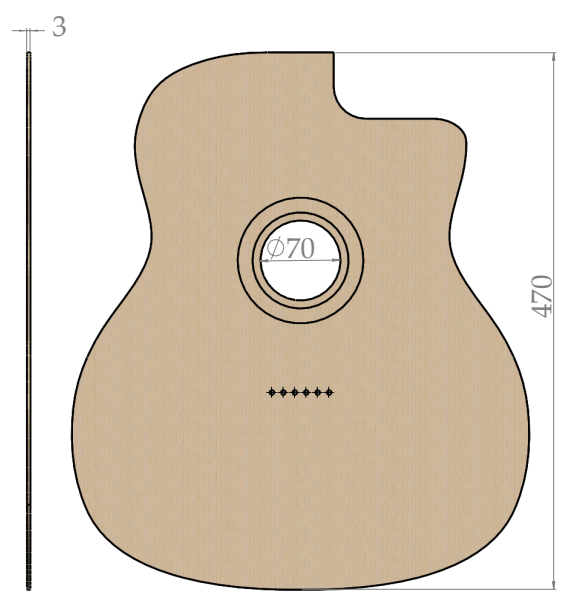

(a)

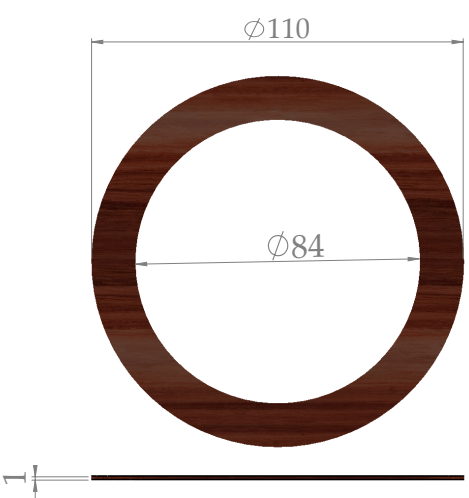

(b)

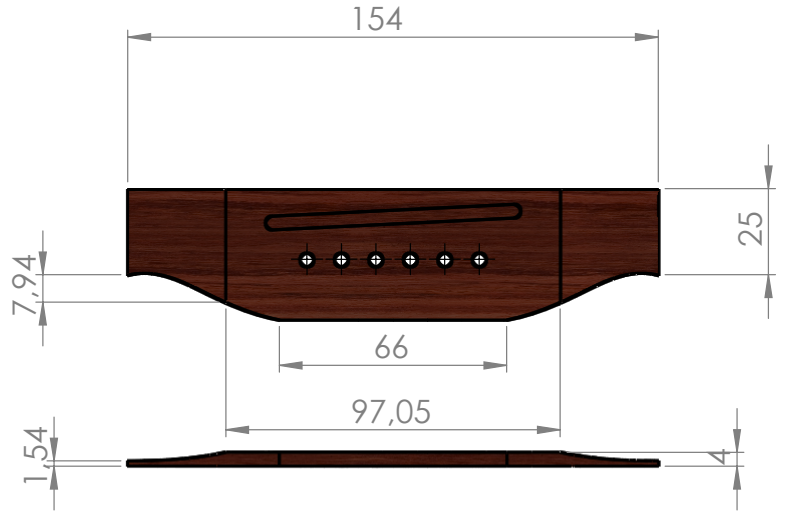

(c) 
TABLE 4 - Name and description of the parameters considered for the analysis.

\begin{tabular}{cc} 
Name & Description \\
\hline$S b_{E_{L}}$ & Soundboard $E_{L}(\mathrm{MPa})$ \\
$S b_{E_{R}}$ & Soundboard $E_{R}(\mathrm{MPa})$ \\
$S b_{G_{L R}}$ & Soundboard $G_{L R}(\mathrm{MPa})$ \\
$S b_{G_{R T}}$ & Soundboard $G_{R T}(\mathrm{MPa})$ \\
$S b_{G_{T L}}$ & Soundboard $G_{T L}(\mathrm{MPa})$ \\
$S b_{\rho}$ & Soundboard density $\left(\mathrm{g} \mathrm{cm}^{-3}\right)$ \\
$\operatorname{Bars}_{E_{L}}$ & Bars $E_{L}(\mathrm{MPa})$ \\
$\operatorname{Bars}_{E_{R}}$ & Bars $E_{R}(\mathrm{MPa})$ \\
$\operatorname{Bars}_{G_{L R}}$ & Bars $G_{L R}(\mathrm{MPa})$ \\
$\operatorname{Bars}_{G_{R T}}$ & Bars $G_{R T}(\mathrm{MPa})$ \\
$\operatorname{Bars}_{G_{T L}}$ & Bars $G_{T L}(\mathrm{MPa})$ \\
$\operatorname{Bars}_{\rho}$ & Bars density $\left(\mathrm{gcm}{ }^{-3}\right)$ \\
$\mathrm{T}$ & Temperature $\left({ }^{\circ} \mathrm{C}\right)$ \\
$\mathrm{RH}$ & Relative humidity $(\%)$ \\
\hline
\end{tabular}

FIGURE 3 - Bridge admittance evaluation and input force position and direction.

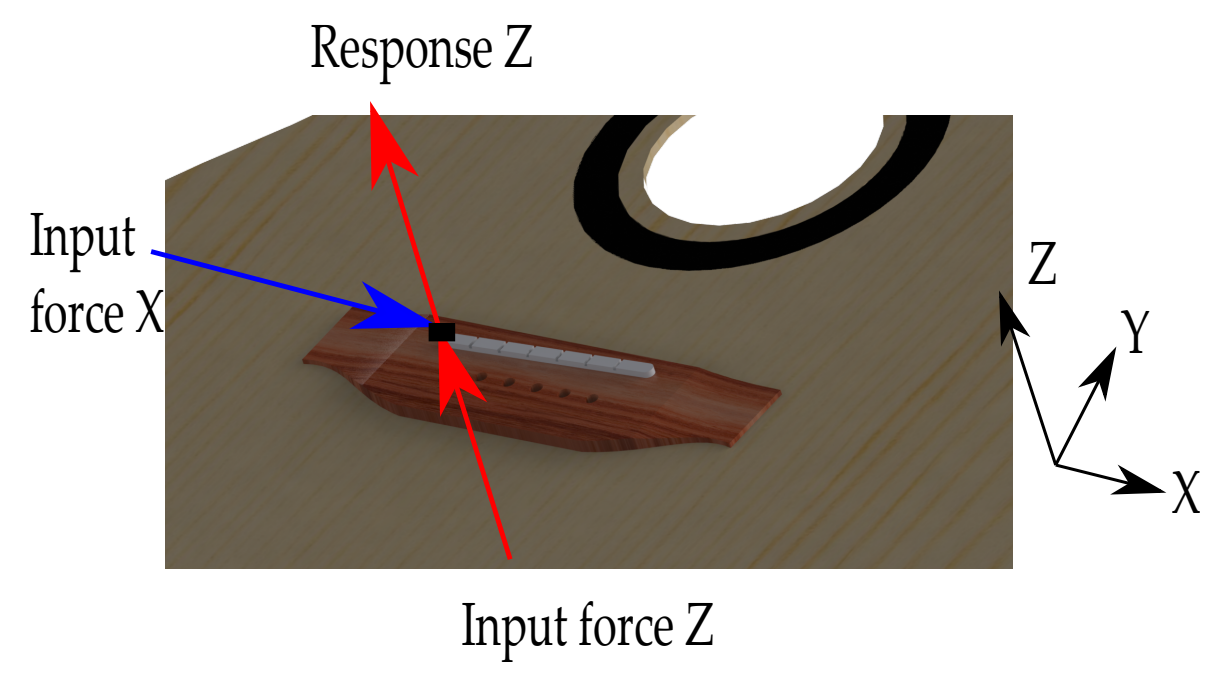


Figure 4 - Computed modes of the classical braces guitar soundboard, $C_{\text {guitar }}$.

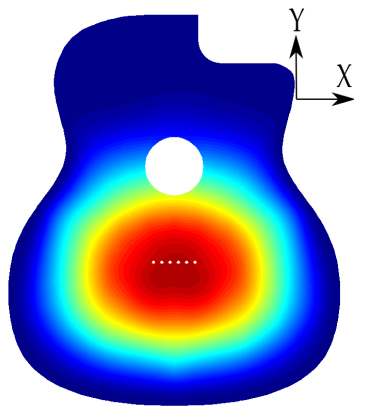

(1) $219.4 \mathrm{~Hz}$

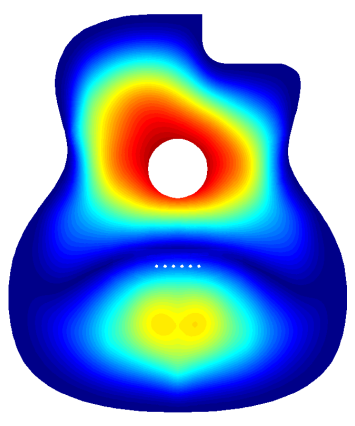

(3) $407.6 \mathrm{~Hz}$

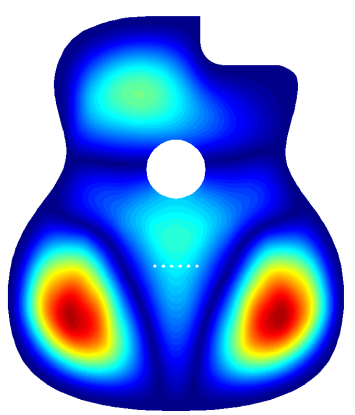

(5) $544.1 \mathrm{~Hz}$

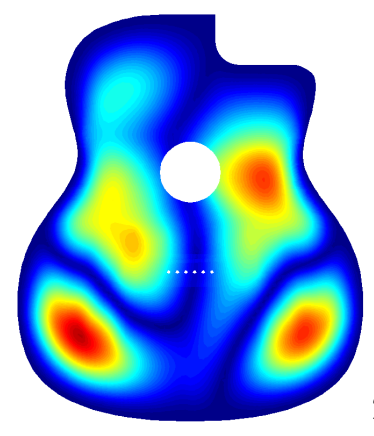

(7) $742.3 \mathrm{~Hz}$

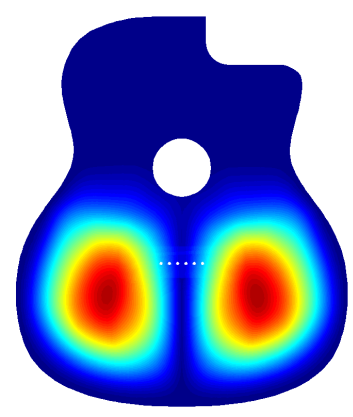

(2) $359.5 \mathrm{~Hz}$

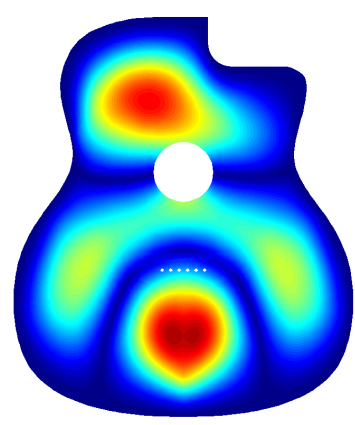

(4) $508.6 \mathrm{~Hz}$

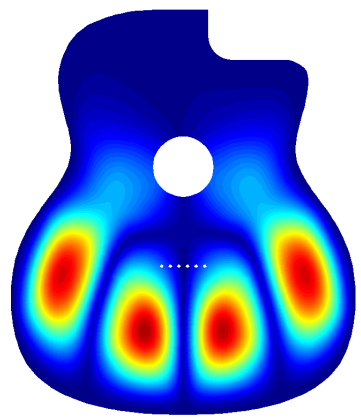

(6) $653.8 \mathrm{~Hz}$

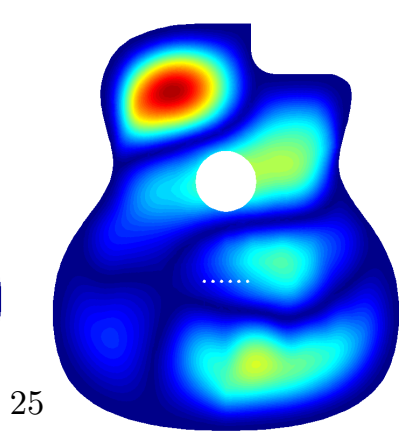

(8) $762.0 \mathrm{~Hz}$ 
Figure 5 - Computed modes of the string-steel braces guitar soundboard, $A_{\text {guitar }}$.

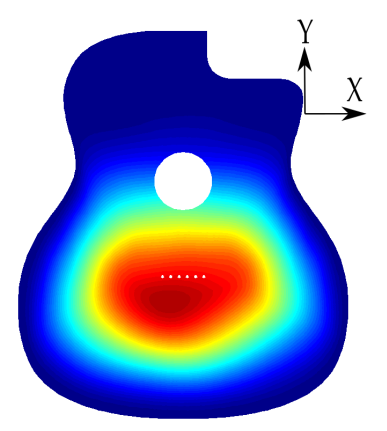

(1) $171.1 \mathrm{~Hz}$

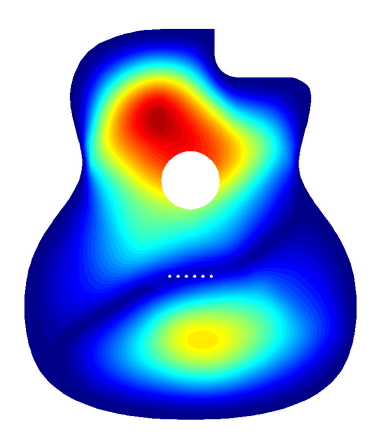

(3) $451.7 \mathrm{~Hz}$

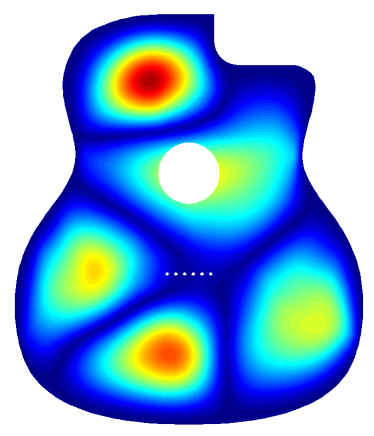

(5) $752.8 \mathrm{~Hz}$

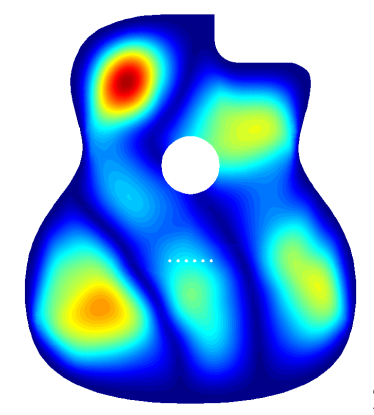

(7) $854.5 \mathrm{~Hz}$

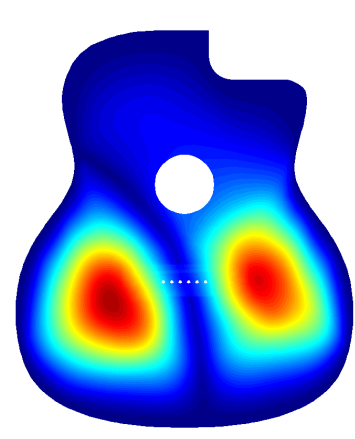

(2) $416.6 \mathrm{~Hz}$

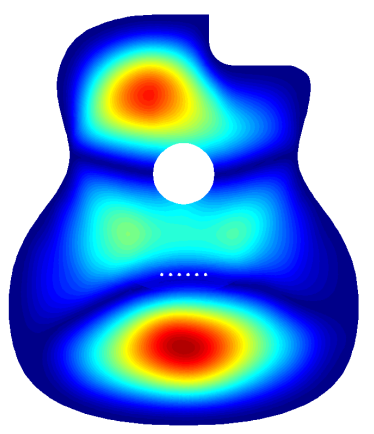

(4) $519.2 \mathrm{~Hz}$

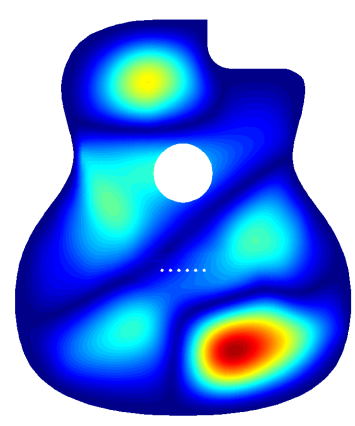

(6) $783.5 \mathrm{~Hz}$

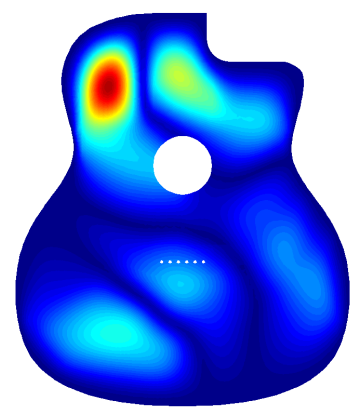

(8) $893.3 \mathrm{~Hz}$ 
Figure 6 - Computed modes of the selmer braces guitar soundboard, $S_{\text {guitar }}$.

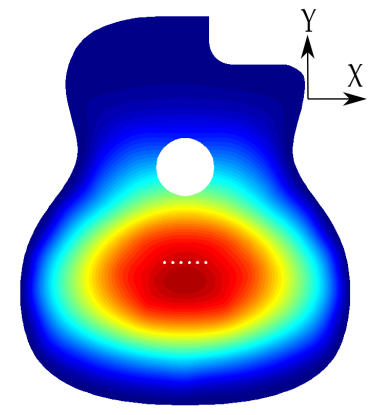

(1) $295.0 \mathrm{~Hz}$

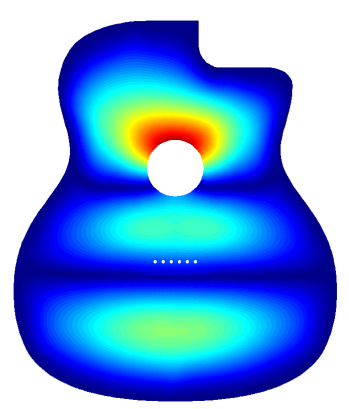

(3) $542.0 \mathrm{~Hz}$

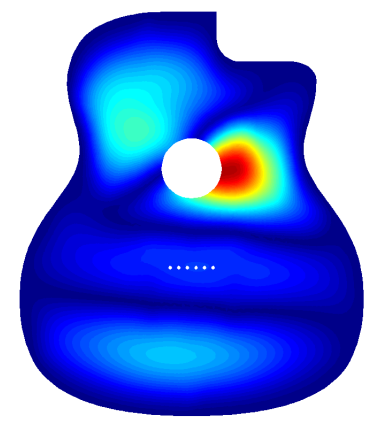

(5) $745.9 \mathrm{~Hz}$

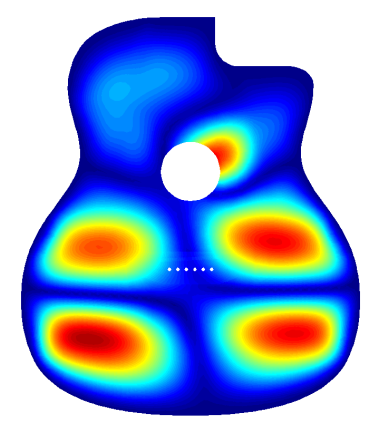

(7) $941.7 \mathrm{~Hz}$

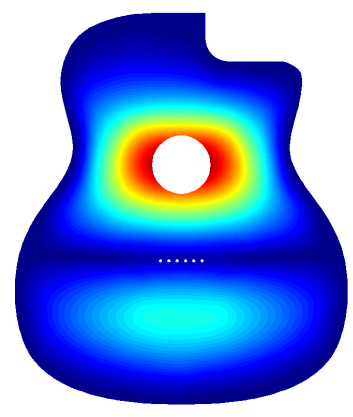

(2) $411.3 \mathrm{~Hz}$

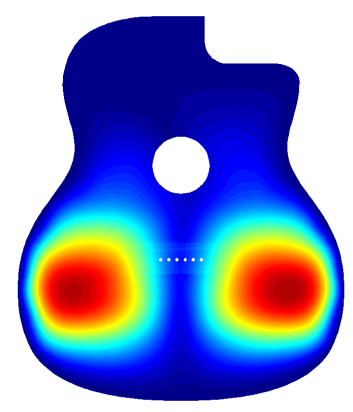

(4) $661.2 \mathrm{~Hz}$

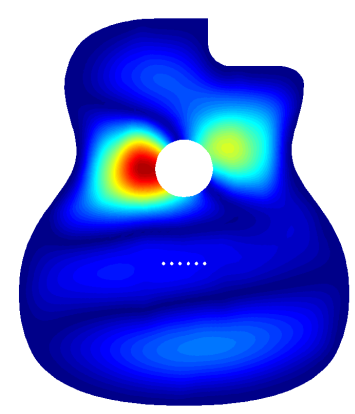

(6) $764.7 \mathrm{~Hz}$

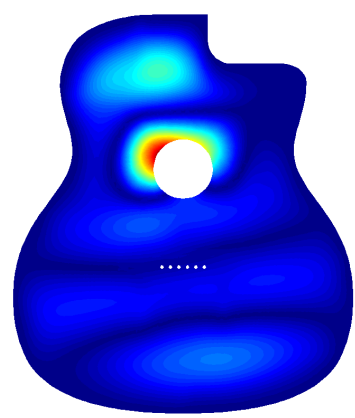

(8) $976.5 \mathrm{~Hz}$

27 
FiguRE 7 - Nominal FRF with inital material and climatic parameters.

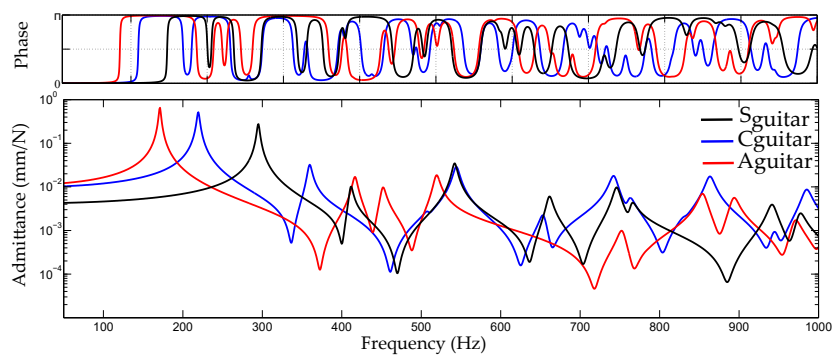

TABLE 5 - Matched eigenfrequencies error (MEE) and MAC value of the three cases with nominal values of the parameters.

\begin{tabular}{|c|c|c|c|c|c|}
\hline & $C_{\text {guitar }}$ & & $S_{\text {guitar }}$ & & \\
\hline Mode & Frequency $(\mathrm{Hz})$ & Mode & Frequency $(\mathrm{Hz})$ & MEE $(\%)$ & MAC $(\%)$ \\
\hline 1 & 214.6 & 1 & 288.7 & 34.5 & 98.9 \\
\hline 2 & 353.5 & 4 & 645.0 & 82.5 & 88.1 \\
\hline \multirow[t]{2}{*}{3} & 400.3 & 2 & 403.5 & 0.8 & 89.9 \\
\hline & $C_{\text {guitar }}$ & & $A_{\text {guitar }}$ & & \\
\hline Mode & Frequency $(\mathrm{Hz})$ & Mode & Frequency $(\mathrm{Hz})$ & MEE. (\%) & MAC $(\%)$ \\
\hline 1 & 214.6 & 1 & 167.5 & -22.0 & 99.5 \\
\hline 2 & 353.5 & 2 & 407.4 & 15.3 & 87.7 \\
\hline 3 & 400.3 & 3 & 442.7 & 10.6 & 88.3 \\
\hline 4 & 501.0 & 4 & 512.3 & 2.3 & 65.0 \\
\hline 8 & 750.8 & 6 & 770.6 & 2.6 & 55.4 \\
\hline 10 & 844.6 & 8 & 873.5 & 3.4 & 52.5 \\
\hline \multirow[t]{2}{*}{12} & 965.5 & 9 & 953.5 & -1.2 & 58.7 \\
\hline & $S_{\text {guitar }}$ & & $A_{\text {guitar }}$ & & \\
\hline Mode & Frequency $(\mathrm{Hz})$ & Mode & Frequency $(\mathrm{Hz})$ & MEE (\%) & MAC $(\%)$ \\
\hline 1 & 288.7 & 1 & 167.5 & -42.0 & 99.2 \\
\hline 2 & 403.5 & 3 & 442.7 & 9.7 & 73.0 \\
\hline 3 & 532.7 & 4 & 512.3 & -3.8 & 76.9 \\
\hline 4 & 645.0 & 2 & 407.4 & -36.8 & 84.2 \\
\hline
\end{tabular}


Figure 8 - Material screening analysis on matched eigenfrequencies of : (a) $C_{\text {guitar }}$, (b) $A_{\text {guitar }}$ (c) $S_{\text {guitar }}$.

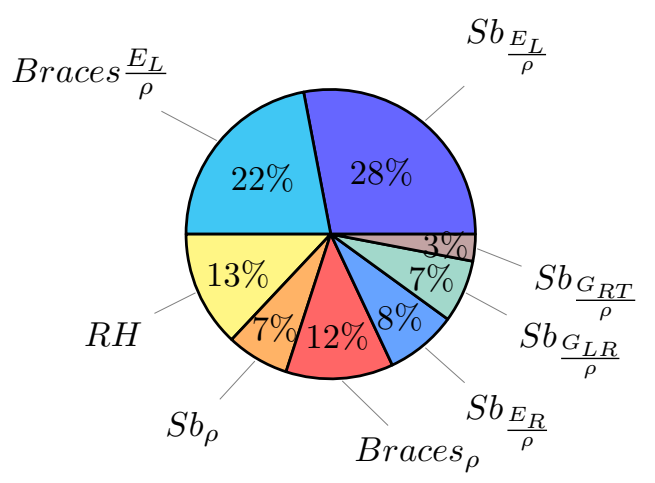

(a)

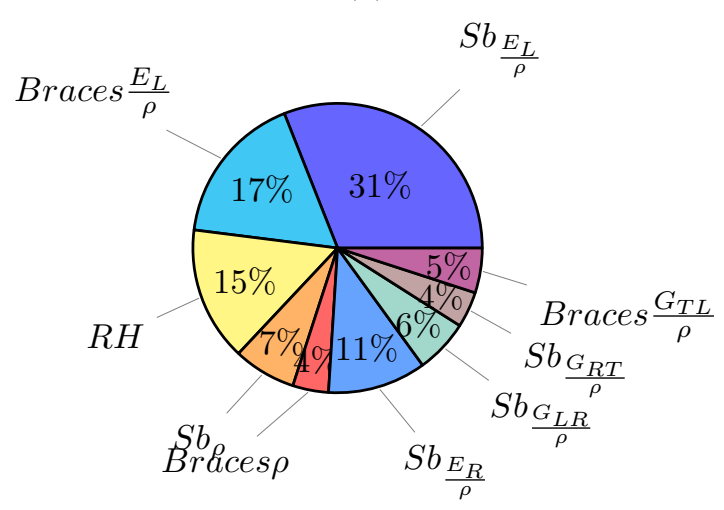

(b)

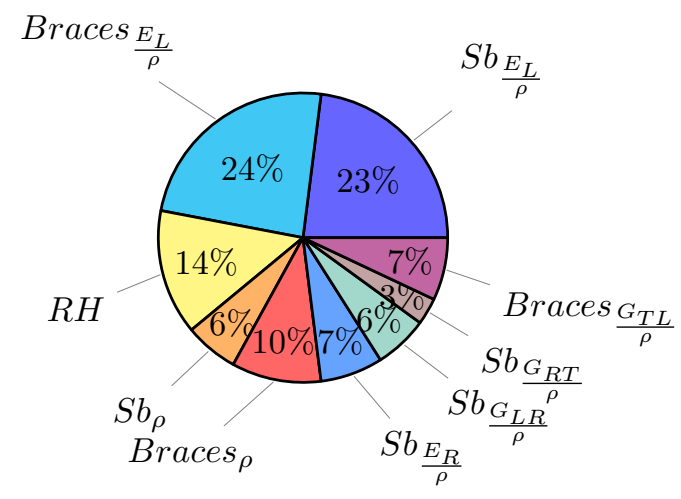

(c) 
TABLE 6 - Values of modal overlap factor (\%) for corresponding third octaves bands for different cases of guitar bars and frequency domain.

\begin{tabular}{ccccc} 
Third octave band (Hz) & $C_{\text {guitar }}(\%)$ & $A_{\text {guitar }}(\%)$ & $S_{\text {guitar }}(\%)$ & Domain \\
\hline 160 & 0 & 9 & 0 & L.F. \\
200 & 7 & 0 & 0 & L.F. \\
250 & 2 & 0 & 3 & L.F. \\
315 & 7 & 0 & 3 & L.F. \\
400 & 14 & 14 & 2 & L.F. \\
500 & 18 & 16 & 9 & L.F. \\
630 & 16 & 9 & 14 & L.F. \\
800 & 37 & 32 & 21 & M.F./L.F. \\
1000 & 39 & 34 & 28 & M.F./L.F. \\
1250 & 48 & 46 & 46 & M.F. \\
1600 & 83 & 96 & 70 & H.F./M.F. \\
2000 & 101 & 97 & 87 & H.F. \\
2500 & 152 & 143 & 124 & H.F. \\
\hline
\end{tabular}

Figure 9 - Modal overlap factor as a function of the third octave bands, for three different cases of guitar bars

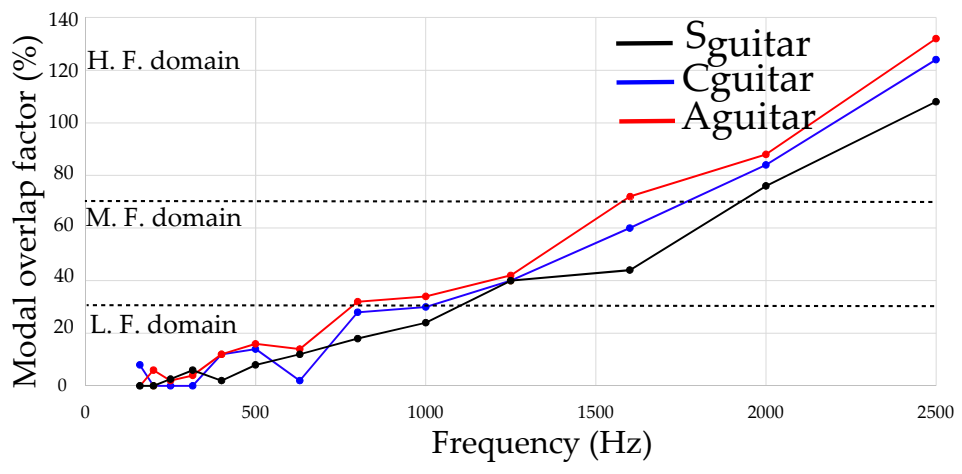


TABLE 7 - Frequency mean values and absolute and relative standard deviation (RSD) of the three cases for a normal distribution of the frequencies.

\begin{tabular}{c|cc|cc|cc} 
Mode & \multicolumn{2}{|c}{$C_{\text {guitar }}$} & \multicolumn{2}{c}{$A_{\text {guitar }}$} & \multicolumn{2}{c}{$S_{\text {guitar }}$} \\
& $\mu$ and SD (Hz) & RSD (\%) & $\mu$ and SD (Hz) & RSD (\%) & $\mu$ and SD (Hz) & RSD (\%) \\
\hline Mode 1 & $215.9 \pm 11.3$ & \pm 5.1 & $168.9 \pm 9.2$ & \pm 5.5 & $291.1 \pm 16.5$ & \pm 5.6 \\
Mode 2 & $355.9 \pm 19.5$ & \pm 5.4 & $413.9 \pm 23.8$ & \pm 5.7 & $406.1 \pm 22.3$ & \pm 5.4 \\
Mode 3 & $403.4 \pm 21.3$ & \pm 5.2 & $448 \pm 24.6$ & \pm 5.5 & $534 \pm 28.8$ & \pm 5.3 \\
Mode 4 & $502.5 \pm 27.3$ & \pm 5.4 & $511.1 \pm 29.2$ & \pm 5.7 & $658.1 \pm 40.0$ & \pm 6.0 \\
Mode 5 & $541.5 \pm 29.1$ & \pm 5.3 & $743.5 \pm 40.1$ & \pm 5.4 & $731.9 \pm 40.6$ & \pm 5.2 \\
Mode 6 & $653.9 \pm 37.8$ & \pm 5.8 & $774.4 \pm 42.6$ & \pm 5.5 & $757.7 \pm 42.3$ & \pm 5.3 \\
Mode 7 & $737.1 \pm 40.0$ & \pm 5.4 & $848.7 \pm 46.5$ & \pm 5.5 & $930 \pm 51.1$ & \pm 5.3 \\
Mode 8 & $750.8 \pm 42.8$ & \pm 5.7 & $888.5 \pm 49.6$ & \pm 5.6 & $960.9 \pm 55.2$ & \pm 5.6 \\
Mode 9 & $832.9 \pm 49.6$ & \pm 5.6 & $959.4 \pm 54.8$ & \pm 5.7 & $1101 \pm 60.8$ & \pm 5.4 \\
Mode 10 & $858.4 \pm 45.9$ & \pm 5.3 & $1006 \pm 57.6$ & \pm 5.7 & $1159 \pm 64.8$ & \pm 5.5 \\
Avg : & - & \pm 5.4 & - & \pm 5.6 & - & \pm 5.5 \\
\hline
\end{tabular}

FiguRE 10 - Mean and upper and lower limits for each case of braces.

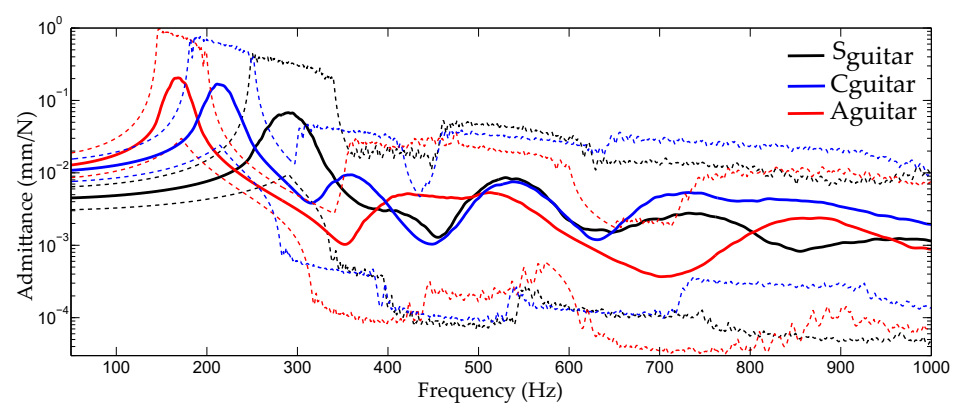


FIgURE 11 - Fuzzy FRF of the bridge admittance for : (a) $C_{\text {guitar }}$, (b) $A_{\text {guitar }}$, (c) $S_{\text {guitar }}$.

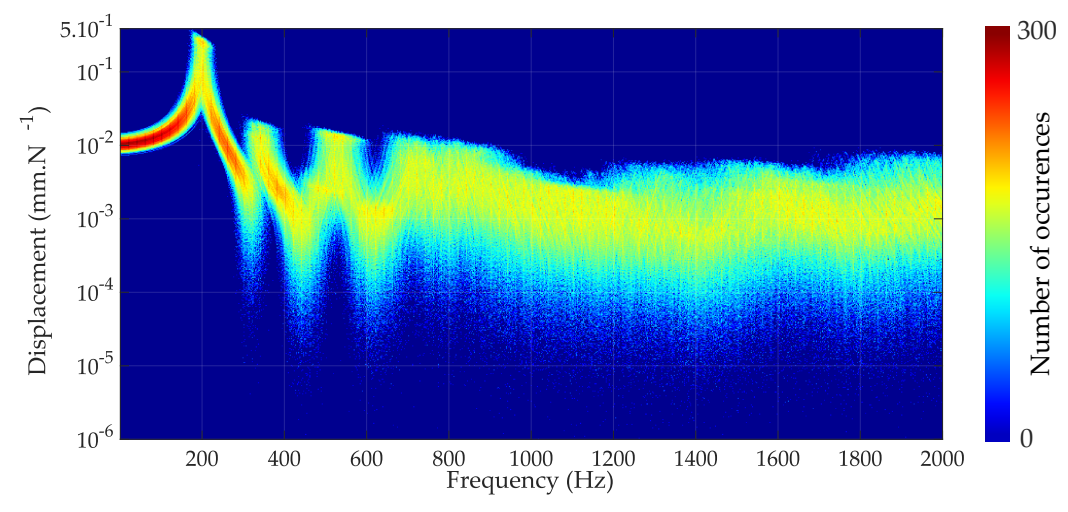

(a)

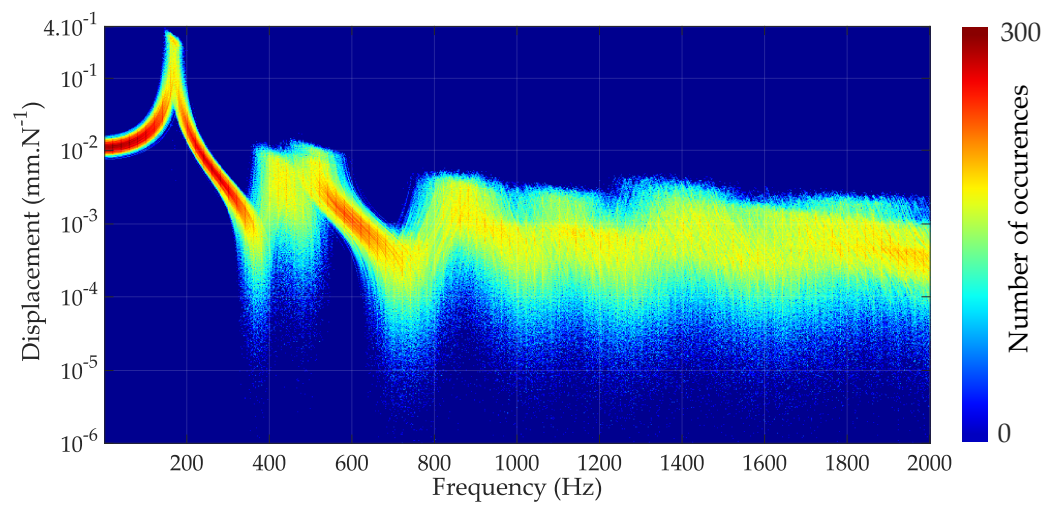

(b)

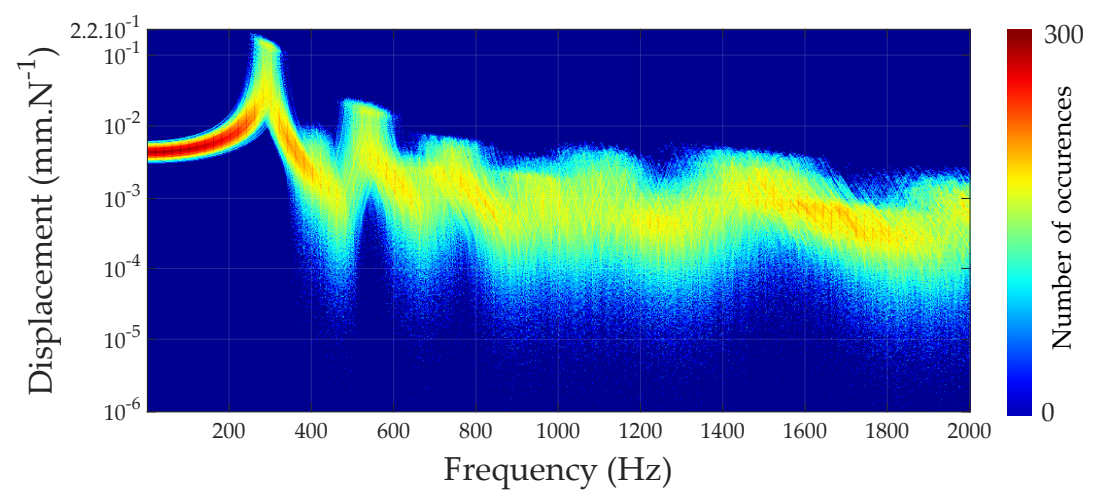

(c) 
FIgURE 12 - Coefficient of correlation between bridge admittance and material parameters :

(a) $C_{\text {guitar }}$, (b) $A_{\text {guitar }}$, (c) $S_{\text {guitar }}$.

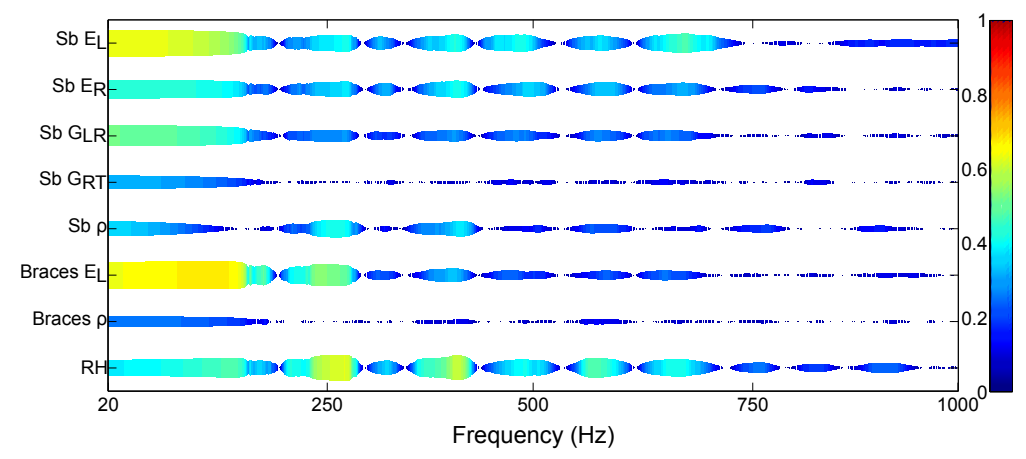

(a)

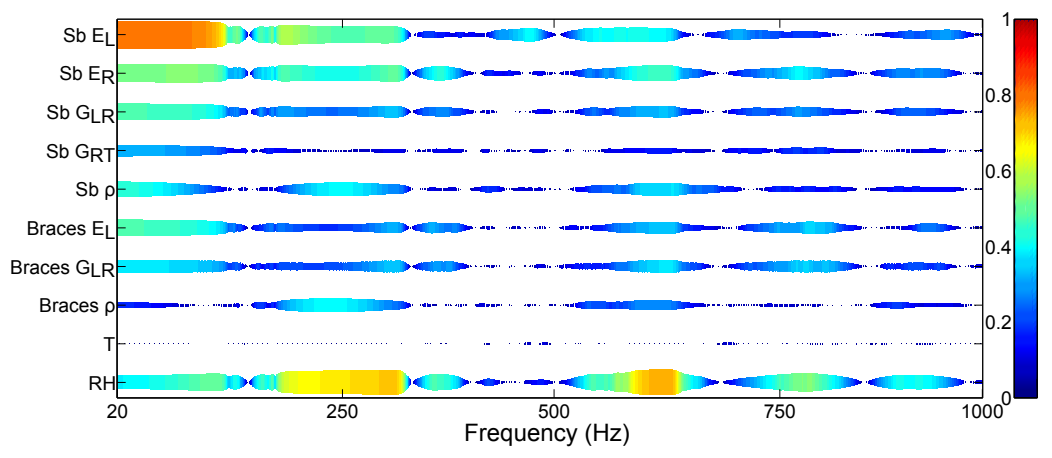

(b)

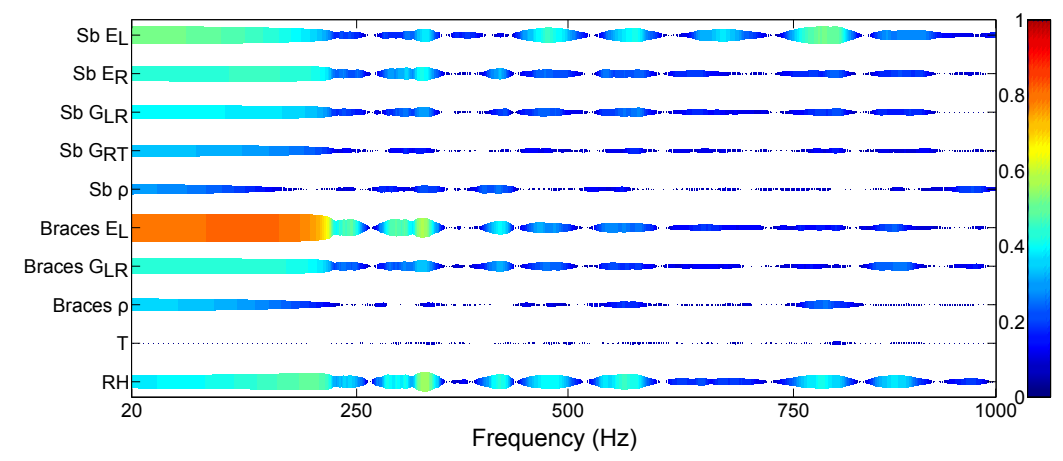

(c) 